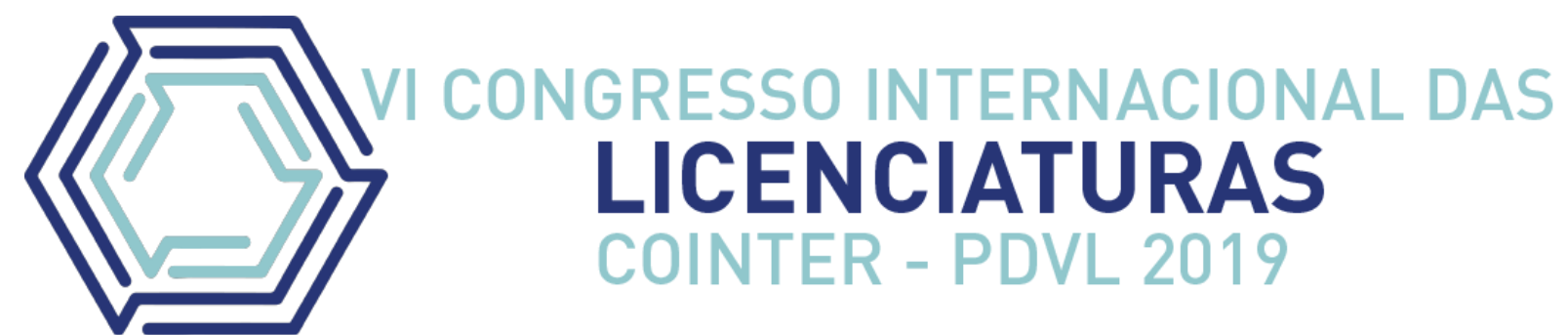

\title{
PROFESSORES DE CIÊNCIAS DA ZONA RURAL DE URUÇUÍ-PI: PERFIL PROFISSIONAL E NOVAS ESTRATÉGIAS DE ENSINO
}

\section{PROFESSORES DE CIENCIAS DEL ÁREA URUÇUÍ-PI RURAL: PERFIL PROFESIONAL Y NUEVAS ESTRATEGIAS DE ENSEÑANZA}

\section{SCIENCE TEACHERS OF THE RURAL AREA OF URUÇUÍ-PI: PROFESSIONAL PROFILE AND NEW TEACHING STRATEGIES}

\author{
Apresentação: Comunicação Oral \\ Laura Cristina Ferreira dos Santos ${ }^{1}$; Ianaely Ingrid Alves e Silva ${ }^{2}$; Ícaro Fillipe de Araújo \\ Castro $^{3}$; Anelise dos Santos Mendonça ${ }^{4}$
}

DOI: $\underline{\text { https://doi.org/10.31692/2358-9728.VICOINTERPDVL.2019.0048 }}$

\begin{abstract}
Resumo
As aulas tradicionais ainda são frequentes no contexto do ensino de ciências, o que as tornam desinteressantes e desmotivadoras. A qualidade do ensino provido pelos sistemas escolares às crianças e jovens tem sido objeto de debates ao longo de várias décadas, culminando com os chamados para a reforma desses sistemas e dos currículos vigentes. O presente trabalho objetivou caracterizar o perfil dos educadores de ciências de escolas municipais localizadas na zona rural de Uruçuí-PI e evidenciar a importância da formação continuada dos docentes para a ampliação da qualidade do processo de ensino-aprendizagem nessa disciplina. Realizou-se uma pesquisa de finalidade básica, de natureza observacional, com abordagem qualitativa do tipo pesquisa de campo, na qual teve como público-alvo professores de Ciências do $6^{\circ}$ ao $9^{\circ}$ ano do ensino fundamental de três escolas municipais localizadas nas comunidades Sangue, Pratinha e Malícia. Destaca-se, assim como os seguintes procedimentos: a técnica de entrevista, questionários aplicados, pesquisa documental e análise de dados, o que permitiu a construção satisfatória dos resultados. É necessário que os professores adotem novas abordagens metodológicas que tornem os assuntos compreensíveis e interessantes para os alunos e que evidenciem a relevância da aprendizagem de tais conteúdos para o cotidiano. Em linhas gerais, verificou-se que ainda existe uma grande proporção de professores que se adequam ao ensino tradicional, devido à falta de conhecimento de outras práticas pedagógicas voltadas para ensino de Ciências/Biologia, além da precariedade de determinados assuntos nos curso de graduação. Dessa forma, faz-se necessárias políticas de incentivo a programas de formação continuada,

\footnotetext{
${ }^{1}$ Acadêmica do curso de Licenciatura em Ciências Biológicas, Instituto Federal do Piauí - Campus Uruçuí, e-mail: lau_cristinabl@hotmail.com

${ }^{2}$ Acadêmica do curso de Licenciatura em Ciências Biológicas, Instituto Federal do Piauí - Campus Uruçuí, e-mail: ianaellyingrid@hotmail.com

${ }^{3}$ Professor do Ensino Básico, Técnico e Tecnológico do Instituto Federal do Piauí - Campus Uruçuí, e-mail: icaro.castro@ifpi.edu.br

${ }^{4}$ Professora do Ensino Básico, Técnico e Tecnológico do Instituto Federal do Triângulo Mineiro - Campus Avançado Uberaba Parque Tecnológico, e-mail: anelisemendonca@iftm.edu.br
} 
assim como maior facilidade de acesso a revistas e jornais científicos e internet.

Palavras-Chave: Ensino de Ciências, Ensino tradicional, Rede pública de ensino.

\begin{abstract}
Resumen
Las clases tradicionales siguen siendo frecuentes en el contexto de la educación científica, lo que las hace poco interesantes y desmotivadoras. La calidad de la educación ofrecida por los sistemas escolares a niños y jóvenes ha sido objeto de debate durante varias décadas, culminando con los llamados a la reforma de estos sistemas y planes de estudio existentes. El presente trabajo tuvo como objetivo caracterizar el perfil de los educadores en ciencias de las escuelas municipales ubicadas en las zonas rurales de Uruçuí-PI y resaltar la importancia de la formación continua del profesorado para aumentar la calidad del proceso de enseñanzaaprendizaje en esta disciplina. Se realizó una investigación observacional de propósito básico con un enfoque cualitativo para la investigación de campo. El público objetivo fueron los profesores de ciencias de sexto a noveno grado de tres escuelas primarias ubicadas en las comunidades de Sangue, Pratinha y Malícia. Destaca, así como los siguientes procedimientos: la técnica de entrevista, los cuestionarios aplicados, la investigación documental y el análisis de datos, que permitieron la construcción satisfactoria de los resultados. Los maestros deben adoptar nuevos enfoques metodológicos que hagan que las materias sean comprensibles e interesantes para los estudiantes y enfaticen la relevancia de aprender dichos contenidos para la vida cotidiana. En general, se encontró que todavía hay una gran proporción de docentes adecuados para la educación tradicional, debido a la falta de conocimiento de otras prácticas pedagógicas dirigidas a la enseñanza de la Ciencias/Biología, además de la precariedad de ciertas materias en el curso de pregrado. Por lo tanto, es necesario fomentar políticas para programas de educación continua, así como un mayor acceso a revistas científicas y revistas e internet.
\end{abstract}

Palabras Clave: Enseñanza de las Ciências, Educación tradicional, Escuela pública.

\begin{abstract}
Traditional classes are still frequent in the context of science education, which makes them uninteresting and demotivating. The quality of education provided by school systems to children and youth has been the subject of debate over several decades, culminating in the calls for reform of these systems and existing curricula. The present work aimed to characterize the profile of science educators of municipal schools located in the rural area of Uruçuí-PI and to highlight the importance of the continuing education of teachers to increase the quality of the teaching-learning process in this discipline. An observational basic purpose research with a qualitative field research approach was carried out. The target audience was Science teachers from 6th to 9th grade of three elementary schools located in the Sangue, Pratinha communities and Malice. It stands out, as well as the following procedures: the interview technique, applied questionnaires, documentary research and data analysis, which allowed the satisfactory construction of the results. Teachers need to adopt new methodological approaches that make subjects understandable and interesting to students and highlight the relevance of learning such contents to everyday life. In general, it was found that there is still a large proportion of teachers who are suitable for traditional teaching, due to the lack of knowledge of other pedagogical practices directed to Science/Biology teaching, besides the precariousness of certain subjects in
\end{abstract}


the undergraduate course. Thus, it is necessary to encourage policies for continuing education programs, as well as greater access to journals and scientific journals and the internet.

Keywords: Science Education, Traditional Education, Public School.

\section{Introdução}

A qualidade do ensino provido pelos sistemas escolares às crianças e jovens tem sido objeto de debates ao longo de várias décadas, culminando com os chamados para a reforma desses sistemas e dos currículos vigentes. $\mathrm{Na}$ atualidade a educação ainda apresenta inúmeras características de um ensino tradicional, no qual o professor é visto como detentor do saber, enquanto os alunos são considerados sujeitos passivos no processo de ensino e aprendizagem (NICOLA e PANIZ, 2016).

É necessário que os professores adotem novas abordagens metodológicas que tornem os assuntos compreensíveis e interessantes para os alunos e que evidenciem a relevância da aprendizagem de tais conteúdos para o cotidiano (HODSON, 2008; HOOLBROK; RANNIKMAE, 2009). Uma das condições a que devem obedecer às metodologias que buscam inovar o ensino de Ciências é a de permitir que os alunos estejam no centro do processo de ensino-aprendizagem e assumam um papel ativo na aprendizagem dos assuntos científicos (PRINCE, 2004).

No ensino tradicional, o professor se vê no centro do aprendizado sendo o aluno um mero expectador que recebe as "verdades absolutas" dos docentes sem abrir espaço para questionamentos e discussões, o que pode gerar diversos problemas no processo de ensinoaprendizagem (FREIRE, 1996). As aulas tradicionais ainda continuam frequentes no contexto das Ciências/Biologia, sendo essa disciplina muitas vezes desinteressante e desmotivadora.

Além do fator supracitado, escolas brasileiras ainda padecem com a falta de recursos financeiros que poderiam auxiliar os professores em suas atividades e melhorar sua prática pedagógica favorecendo o processo educativo. Convém lembrar da ausência de capacitação continuada que pode influenciar diretamente no constante uso de metodologias tradicionais no ensino de Ciências.

De acordo com as Diretrizes Curriculares da Educação Básica, as dificuldades na formação inicial ou a carência de formação continuada do professor podem tornar obstáculos ao processo de ensino-aprendizagem. A falta de fundamentação teórico-metodológica dificulta uma seleção coerente de conteúdo, bem como inviabiliza um trabalho crítico-analítico com o livro didático adotado (PARANÁ, 2008). Além disso, a Educação Básica trabalha com o 
conhecimento científico, o qual, ao passar por uma transposição didática, é transformado em saber escolar. Para tanto, é imprescindível que o professor tenha se apropriado destes conhecimentos para que possa mediar o processo de ensino-aprendizagem junto ao aluno (CARVALHO, 2010).

No que se referem à Educação do Campo, as dificuldades educacionais são mais acentuadas, em razão da carência de condições materiais, como infraestrutura adequada e material teórico-metodológico, bem como o fato de ainda estar se formando um entendimento de que os alunos que vivem e estudam no contexto do campo (BARRADAS, 2013). Pesquisas que buscam conhecer o perfil de docentes de Ciências, principalmente em comunidades rurais, são escassas, porém são importantes ferramentas para o entendimento da realidade e qualidade do ensino local.

O objetivo deste trabalho foi caracterizar o perfil dos educadores de Ciências do Ensino Fundamental de escolas municipais localizadas na Zona Rural de Uruçuí-PI (Comunidades Sangue, Pratinha e Malícia) e evidenciar a importância da formação continuada de docentes para o ensino de Ciências.

\section{Fundamentação Teórica}

\section{Ensino na Zona Rural}

A origem da Educação do Campo está atrelada a Educação Rural, que no Brasil emerge da necessidade de distintos grupos sociais em acessar a educação. "As escolinhas" criadas no meio rural, geralmente multisseriadas e isoladas, eram poucas e questionadas pelas forças hegemônicas da sociedade quanto a sua eficácia no ensino" (ANTONIO e LUCINI, 2007, p. 179).

As classes multisseriadas têm alunos de diferentes séries e níveis em uma mesma sala de aula, independentemente do número de professores responsável pela classe. A unidocência ocorre quando um único professor é responsável pela condução do desenvolvimento de uma classe multisseriada. Embora possa acontecer de uma escola ou classe ser multisseriada e ter mais de um professor, as escolas multisseriadas do campo contam, na quase totalidade dos casos, com apenas um professor, o que torna unidocência e multisserviço termos equivalentes (INEP/MEC, 2007).

Segundo Furtado e Brandão (1999), “a qualidade do ensino ministrado no meio rural, 
pode ser analisada do ponto de vista da precariedade da oferta: instalações, materiais didáticos e principalmente a formação precária e o acompanhamento quase inexistente dos professores em exercício; bem como considerando-se o capital sociocultural em jogo, consequência do isolamento e desamparo histórico a que tem sido submetida a população do meio rural, o que é claramente visível pelo alto índice de analfabetismo”.

As escolas rurais no Brasil, historicamente, têm estado em desvantagem, apresentando menores níveis de escolarização e maiores índices de reprovação, abandono e defasagem idadesérie (VENDRAMINI, 2014). Conforme dados do Departamento Intersindical de Estatística e Estudos Socioeconômicos (DIEESE, 2011), o analfabetismo rural é três vezes maior que o urbano, o que reforça a desigual formação profissional entre os educadores do meio rural e do urbano.

A baixa autoestima está presente como fator determinante de influência negativa na frequência às aulas no Campo. $\mathrm{O}$ aluno gera uma sensação de falta de perspectivas com relação a sua carreira escolar, o que provoca desânimo, falta de motivação e baixa autoestima, como círculo vicioso no meio escolar (ONOFRE, 2007).

É recente no Brasil a formação de educadores do campo e também recentes as pesquisas sobre o trabalho docente no contexto rural. As pesquisas que temos sobre as escolas no campo e o trabalho docente nesse contexto revelam "Professores com pouca formação escolar, com baixa ou nenhuma remuneração, escolas precárias, falta de material, altos índices de evasão, baixa didática e prática de Ensino na relação com a Formação de Professores aproveitamento pedagógico por parte dos alunos, dentre outros" (MARTINS, 1975; CALAZANS, 1979; MAIA, 1982; CENAFOR, 1985; TURFFI, 1988; apud ANTUNES-ROCHA, 2010, p. 76).

Tais escolas apresentam, em geral, currículos pouco adequados à realidade em que se encontram, ou seja, têm como referência o espaço urbano e muitas vezes trabalham em função do êxodo rural ao mostrar a cidade como lugar da civilidade e do progresso.

\section{Perfil do Professor de Ciências}

Vivemos em um mundo globalizado, em que o rápido desenvolvimento científico e tecnológico impõe uma dinâmica de construção e reconstrução de saberes, valores, atitudes e conhecimentos para os seres humanos (FREITAS e VILLANI, 2002).

Porém, ainda não se tem muitas pesquisas que tratem da educação no campo (comparando-se com as que discutem a educação urbana) e menos ainda que tratem da 
formação de seus educadores porque essa formação não existia, o que em geral existia era a ausência de uma preparação específica ou, como alguns documentos apontam, em muitas regiões do país, ainda é uma "formação inadequada".

Diante dessa realidade, observamos que os professores de Ciências precisam de uma formação mais adequada, que vise o ser autônomo, crítico e reflexivo. Com tal formação, ele terá elementos necessários para construir uma dinâmica discursiva em sala de aula mais adequada aos propósitos do ensino de Ciências em nossa sociedade contemporânea, rompendo com o velho padrão que caracteriza as diferentes salas de aula de Ciências. Isso refletirá, dentre outros aspectos, na construção de estratégias adequadas para lidar como bombardeio de informações que a sociedade a todo o momento disponibiliza aos indivíduos (SANTANA, 2012; SILVA et al., 2010).

Santana (2012) e Silva et al. (2010) acreditam que é na formação docente que o professor começa a incorporar atitudes que, aos poucos, constituirão um novo perfil de atuação em sala de aula, enfatizando que a formação continuada como um momento de reflexão e prosseguimento das discussões já desencadeadas.

Pelo o que se observa no texto, "a realidade do campo exige um educador que tenha compromisso, condições teóricas e técnicas para desconstruir as práticas e ideias que forjaram o meio e a escola rural" (ANTUNES-ROCHA, 2010, p. 395). Nesse sentido, as necessidades presentes na escola do campo exigem um profissional com uma formação mais ampliada.

\section{Formação Continuada}

A Política de formação continuada é entendida como a abrangência de vários elementos, entre eles, a formação no interior da própria escola, com os coletivos de profissionais daquela unidade de ensino e suas relações com outras instituições e sujeitos, e não como processos esparsos de qualificação, eventos em grande escala, acontecimentos esporádicos no início do ano letivo, cursos promovidos unilateralmente por parte das secretarias de educação (PARENTE, 2014).

A Formação Continuada é uma exigência da LDB 9.394/96. Os professores necessitam conhecer as leis que regem seus direitos e deveres, para que, assim, possam cobrar mais das autoridades competentes, sejam elas entidades públicas ou privadas.

Portanto é essencial entender que nas escolas do campo existe uma necessidade de professores com uma formação abrangente devido às diferentes dimensões existentes, como 
lembram Antunes-Rocha (2010, p. 395) "a realidade do campo exige um educador que tenha compromisso, condições teóricas e técnicas para desenvolver as práticas e ideias que forjaram o meio e a escola rural".

Por meio da formação continuada o professor poderá entender os problemas de seu cotidiano, agindo de forma consciente em sua prática educativa. Segundo Demo (2007, p. 11) “investir na qualidade da aprendizagem do aluno é, acima de tudo, investir na qualidade docente". Este investimento acontece pela formação continuada dentro e fora da escola. Por exemplo: na escola, por intermédio dos problemas diagnosticados em sala de aula, em reuniões pedagógicas, troca de experiências com professores, são situações diárias de ensino e aprendizagem. Fora da escola o aperfeiçoamento do conhecimento pode acontecer por intermédio de cursos, palestras, entre outros.

A busca constante pela formação continuada por professores de Ciências acontece concomitantemente à busca por novos instrumentos e estratégias metodológicas. Ensinar a "Ciência da Vida" é algo fascinante, mas se esse ensino ocorrer exclusivamente através de aulas expositivas, com conteúdo baseados na memorização, tendo o livro didático como único instrumento pedagógico pode se tornar desinteressante para o aluno. Sabe-se que a aula em que o conhecimento é somente "repassado" não sai do ponto de partida, deixando o aluno como objeto de ensino e instrução. Cabe então ao professor a tarefa de tornar o conteúdo mais interessante e significativo para os alunos (DEMO, 2011).

\section{Metodologia}

Realizou-se uma pesquisa básica, de natureza observacional, com abordagem qualitativa e de campo. Segundo Fontelles et al. (2009), a pesquisa é básica pois há um acúmulo de conhecimentos, sem que haja necessariamente uma aplicação prévia; de natureza observacional porque o investigador atua como mero observador dos fatos, sem realizar qualquer tipo de intervenção; qualitativa pois os aspectos sociais e culturais são observados mediante a descrição dos fatos, sem considerar seus aspectos numéricos e/ou estatísticos; e de campo porque foram utilizadas técnicas observacionais, com utilização de questionários para coleta dos dados.

A mesma teve como público-alvo professoras de Ciências do $6^{\circ}$ ao $9^{\circ}$ ano do Ensino Fundamental de três escolas municipais localizadas em comunidades da Zona Rural de UruçuíPI, sendo elas Sangue, Pratinha e Malícia. Essa escolha se deu pelo fato de os alunos do Ensino 
Fundamental da rede púbica na maioria das vezes se depararem com metodologias de ensino que nem sempre possibilitam um adequado processo de ensino-aprendizagem, principalmente em instituições localizadas em Zonas Rurais, caracterizadas por muitas dificuldades relacionadas ao ensino. Assim, faz-se necessário a execução de projetos que visem conhecer o perfil dos educadores de Ciências na realidade de escolas públicas e auxiliar os docentes na busca por formas inovadoras de ensinar, os incentivando a utilizarem novos instrumentos e metodologias de ensino em sua prática docente.

O procedimento foi realizado com autorização das diretoras das referidas escolas, visto que para participarem deste trabalho, todos os professores(as) foram informados sobre a pesquisa, bem como seus fins e posteriormente assinaram um Termo de Consentimento Livre Esclarecido (TCLE), resguardando anonimato, e eles assegurando a elas a saída da pesquisa a qualquer momento.

Após tais esclarecimentos, participaram da pesquisa seis docentes, sendo todas do sexo feminino com idade entre 30 à 40 anos de idade. As participantes responderam um questionário contendo oito questões, sendo em sua maioria de natureza objetiva, contendo apenas $20 \%$ de questões discursivas, baseada no trabalho de Lima e Vasconcelos (2006), com adaptações dividido em: perfil socioeconômico e formação profissional do professor; metodologia de ensino e avaliação em sala de aula, buscando caracterizar o perfil do docente levantando questões sobre formação acadêmica, tempo de exercício de profissão, atividades profissionais complementares, fontes de informações em Ciências, acesso à tecnologia e biblioteca.

De acordo com Gray (2012), os questionários são uma das técnicas mais usadas de coleta de dados primários, permitindo uma abordagem analítica explorando as relações entre as variáveis, visando à coleta de dados, a partir de um conjunto de questões pré-elaboradas, organizadas de forma sequencial, por escrito ou oralmente, sobre o tema de interesse da pesquisa. Após a análise dos questionários os dados foram sistematizados em gráficos no Microsoft Excel® 2010, para intencionar a assimilação dos resultados da pesquisa.

\section{Resultados e Discussão}

No mês de agosto de 2018 foram preenchidos um total de seis questionários. Os resultados do trabalho mostraram que, em relação ao perfil dos professores há predominância de mulheres (100\%) e de profissionais com curso superior concluído 67\% (Figura 1A). Dentre as entrevistadas, duas são graduadas em Licenciatura em Educação Física, uma em Licenciatura 
em Ciências Biológicas e Bacharelado em Agronomia, e as outras duas em Licenciatura em Geografia e Licenciatura em Matemática, sendo as instituições de ensino superior de origem das graduadas a Universidade Estadual do Piauí - Campus Uruçuí $(66,6 \%)$ e a Universidade Federal do Piauí e Instituto Federal de Educação, Ciências e Tecnologia do Piauí (33,4 \%). De acordo com esses dados, pode-se perceber que de seis professoras que ministram aulas de Ciências/ Biologia apenas uma é formada em Biologia (cerca de 17\%).

Observou-se que 50\% das professoras possuem entre 35 e 45 anos e $33 \%$ possuem mais de 45 anos (Figura 1B). Mais da metade das professoras (67\%) possuem pouca experiência na docência, lecionando há menos de 5 anos (Figura 1C). A faixa salarial da maioria das docentes é, conforme esperada, considerada baixa $(88,1 \%)$ de acordo com os entrevistados. Assim, $11,9 \%$, afirmam necessitar trabalhar em mais de uma escola.

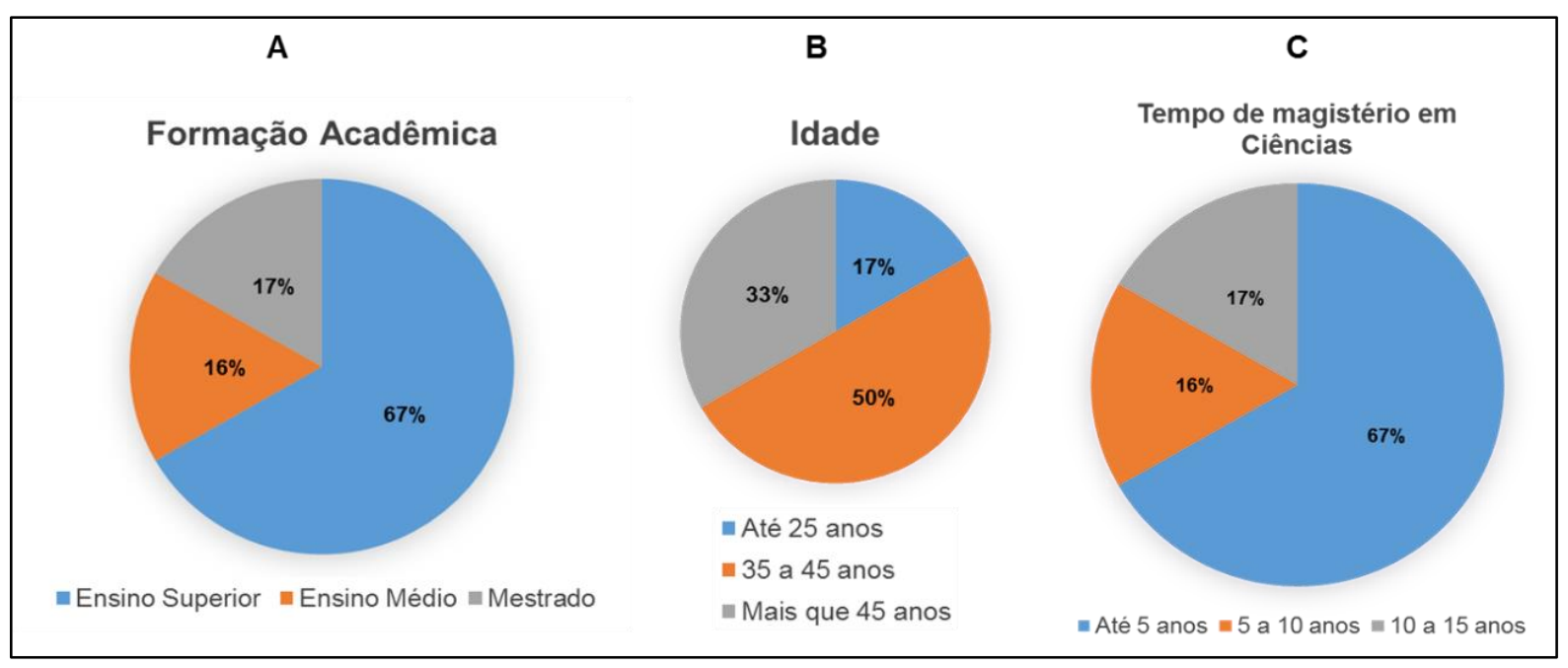

Figura 1: Perfil do professor de Ciências em escolas públicas rurais do município de Uruçuí. Distribuição dos professores de acordo com a sua formação acadêmica (A), idade (B) e tempo de magistério em Ciências (C).

Os livros adotados oficialmente pela Secretaria de Educação da Cidade Uruçuí para serem utilizado durante o ano letivo é o "Ciências da Natureza" de Zuleika de Felice Murrie, $2^{\mathrm{a}}$ edição. Foi observado que as professoras não utilizam outros livros, além do livro didático, para aprofundar o conhecimento de Ciências/Biologia para seus alunos. Cerca de 50\% das entrevistadas afirmaram ter grandes dificuldades em obter maior acervo de material de apoio didático, as quais incluem falta de tempo e falta de livrarias técnicas (90\%) e ausência de bibliotecas especializadas (10\%).

Como fontes complementares de informação em Ciências apenas 67\% das professoras afirmam ler revistas de divulgação científica/educacional, especialmente a revista "Superinteressante", para prepararem suas aulas (Figura 2A). Entre as que afirmaram não 
possuir o hábito de ler revistas de divulgação, 39\% indicaram a falta de tempo como o principal motivo e $38 \%$ atribuíram mudanças de professores que ocorrem com frequência. Ainda como fontes de informação sobre Ciências/Educação, a maioria das docentes (90\%) afirmou não frequentar regularmente bibliotecas especializadas. Questionadas sobre suas fontes de informação específicas em Ciências/Biologia, as professoras manifestaram desconhecimento sobre periódicos científicos, uma vez que nenhuma professora soube citar qualquer revista científica indexada nacional ou internacional em suas respectivas áreas de atuação/interesse.

Em relação à internet, observou-se que $83 \%$ das professoras têm acesso a esta ferramenta (Figura 2B), principalmente na escola (74\%). A internet é utilizada por $67 \%$ das professoras entrevistadas para desenvolver pesquisas sobre Ciências e/ou Educação, como também, elaborar aulas e outras atividades (Figura 2C).

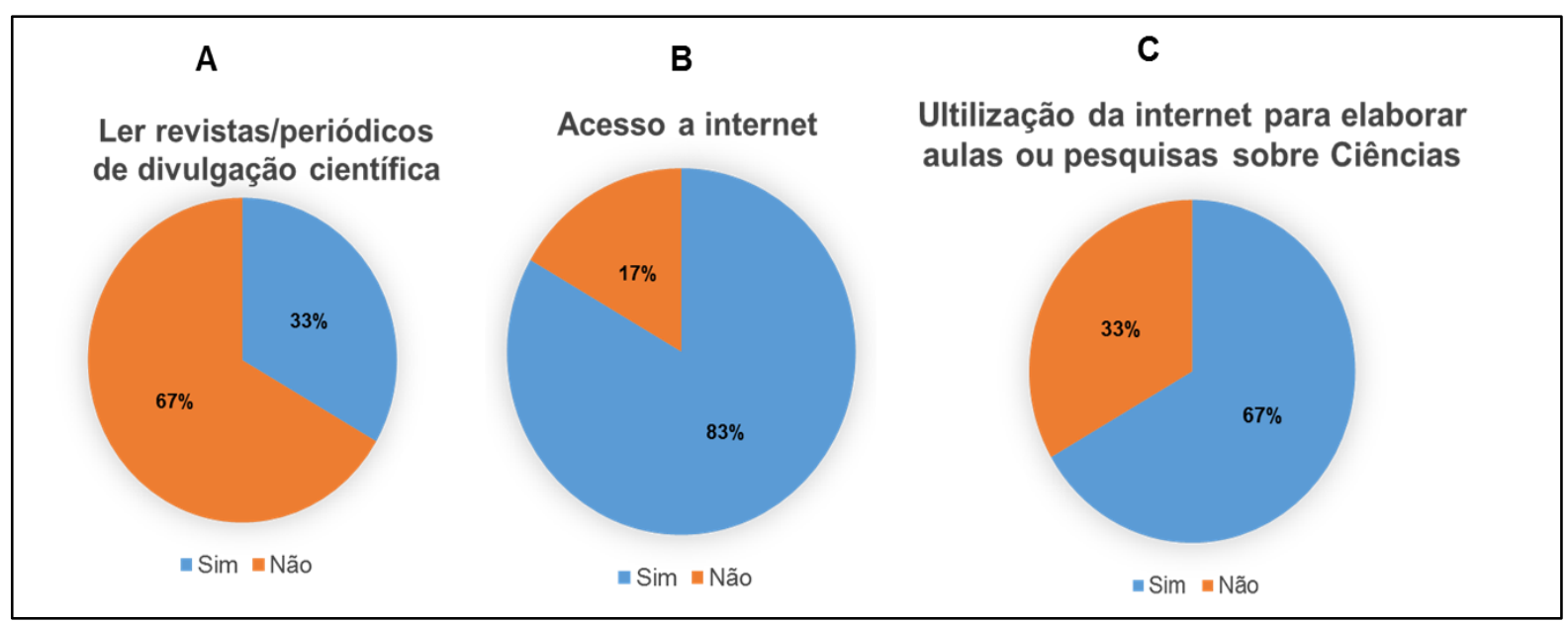

Figura 2: Fontes de informação para o professor de Ciências em escolas públicas rurais do município de Uruçuí. Utilização ou não de revistas/periódico de divulgação científica para elaboração de aulas de Ciências (A), acesso à internet e (B) e a utilização da internet para a elaboração de aulas de Ciências $(\mathbf{C})$.

Quanto aos recursos mantidos pelas escolas que poderiam contribuir para a atualização profissional de professores de Ciências, as entrevistadas destacaram principalmente: cursos e palestras, laboratórios, experimentotecas, coleções zoológicas e herbários (Figura 3A). Porém, cerca de $85 \%$ dos mesmos não possui conhecimento de assuntos teóricos e práticos sobre laboratório para desenvolver aulas mais experimentais e interativas.

De acordo com Bazzo (2000), os objetivos do ensino passaram a relacionar-se com a formação do cidadão, e o uso do laboratório passou a ser bastante incentivado, com o intuito inclusive de despertar nos alunos o "espírito científico". No entanto, embora hoje os professores possam fazer uso de laboratórios com mais facilidade, isso não significa uma garantia de que o ensino de Ciências no Ensino Fundamental ou de Biologia no Ensino Médio aconteça de forma 
mais efetiva, sendo necessário o desenvolvimento de experimentotecas, coleções zoológicas entre outro mecanismo de ensino para o aluno.

Krasilchik (2004) argumenta que no ensino das Ciências, e mais especificamente de Biologia, avaliações baseadas em práticas de laboratório e campo são escassas e ainda mais complexas. Porém os professores não podem desistir ou se limitar a uma forma de ensino, deve sempre buscar motivações e investigação para suas aulas, sendo necessário colocar o aluno no laboratório realizando os experimentos para verificar realmente o que aprendeu e como se comporta frente a um problema concreto.

Ao serem questionadas sobre quais assuntos despertam maior interesse dos alunos do $6^{\circ}$ ao $9^{\circ}$ anos do Ensino Fundamental, as professoras relataram que os temas ligados à sexualidade e reprodução são os que mais prendem a atenção desses alunos. Quando interpeladas sobre quais assuntos sentem mais dificuldade em ensinar, as professoras citaram, principalmente, "Corpo Humano: Citologia e Histologia” e "Noções de Física” (Figura 3B).

Questionadas sobre os motivos para tais dificuldades, as mesmas alegaram falta de recurso didático e deficiências em sua formação profissional, na qual afirmam ter recebido uma base menos aprofundada sobre aqueles temas. Algumas profissionais relataram que não se identificam com determinados assuntos da área de Ciências/Biologia.

Segundo Arroyo (2007), nos cursos de formação de professores, confundem-se a história e a estrutura das escolas como se fosse uma só escola, como se não existissem outros lugares/espaços escolares. Isto porque não se tem uma tradição que pense políticas e práticas contextualizadas.

De acordo com Marques (2010) mesmo possuindo uma licenciatura que habilita para a docência, muitos professores sentem variadas dificuldades no trabalho nas escolas no campo porque tiveram uma formação muito generalista que, de fato, não prepara o licenciado para uma educação específica do campo. As licenciaturas, da forma como organizam seus currículos, contribuem mais para a (con)formação de professores à realidade das escolas no campo como escolas da cidade que para seu repensar.

Desse modo, Geglio (2015), em seus trabalhos deixa claro que e o ensino de Ciências tem como objetivo precípuo capacitar o cidadão para que ele participe coletivamente das oportunidades da sua vida natural e social e que também contribua para que ele seja corresponsável pelas ações que executa no seu cotidiano. O autor ainda enfatiza que com essa visão, a ciência deixa de ter um aspecto neutro, imprevisível e desconexo da realidade, para se 
caracterizar como um marco no processo de construção histórica, econômica e social dos indivíduos. Assim, a ciência abre espaço para um fazer interdisciplinar e deixa de ser concebida meramente como a panaceia para os problemas, bem como a culpada pelas catástrofes que afligem a humanidade.

Além da exposição oral "convencional”, as professoras declararam lançar mão de outros formatos, tais como condução de experimentos (50\%) e visitas didáticas (25\%). No entanto, $25 \%$ das professoras entrevistadas afirmaram não utilizar nenhuma destas atividades (Figura 3C). Quando indagadas sobre o material de apoio didático usado em sala de aula observou-se que livros $(43 \%)$ e vídeos (22\%) são os recursos mais utilizados. O computador já parece estar assumindo um papel relevante nas escolas públicas, uma vez que $21 \%$ das professoras afirmaram utilizá-lo durante as aulas, com a junção de slides 14\% (Figura 3D). No entanto ainda pode se observar que ensino tradicional ainda se destaca nas escolas da zona rural de Uruçuí, no qual o livro tem uma maior relevância de ensino, “deixando de lado" outros de meios de ensino de Ciências/Biologia que possam facilitar o conhecimento dos alunos.

Para Kruger (2003), o Modelo Didático Tradicional é caracterizado por concepções de ensino como uma transmissão/transferência de conhecimentos, por uma aprendizagem receptiva e por um conhecimento absolutista e racionalista. Destas derivam uma prática profissional que concebe os conteúdos de sala de aula como reprodução simplificada do conhecimento científico 'verdadeiro', transmitido verbalmente pelo professor (metodologias transmissivas), por um currículo fechado e organizado de acordo com uma lógica disciplinar e por uma avaliação classificatória e sancionadora. Segundo Lima e Vasconcelos (2006), é necessário quebrar a dependência a este recurso, complementando-o com outras fontes de conhecimento/atualização para o docente, como livros e periódicos científicos.

A metodologia de avaliação mais frequentemente utilizada pelas professoras de Ciências baseia-se em provas. Tais avaliações consistem de questões de múltipla escolha (“objetivas", aplicadas por 34\% das entrevistadas). Percebem-se mudanças em direção a um estilo mais contínuo e diversificado de avaliação, baseado em critérios de participação do aluno nas atividades em sala de aula e fora dela. Outra forma de avaliação utilizada inclui seminários (Figura 3E). 


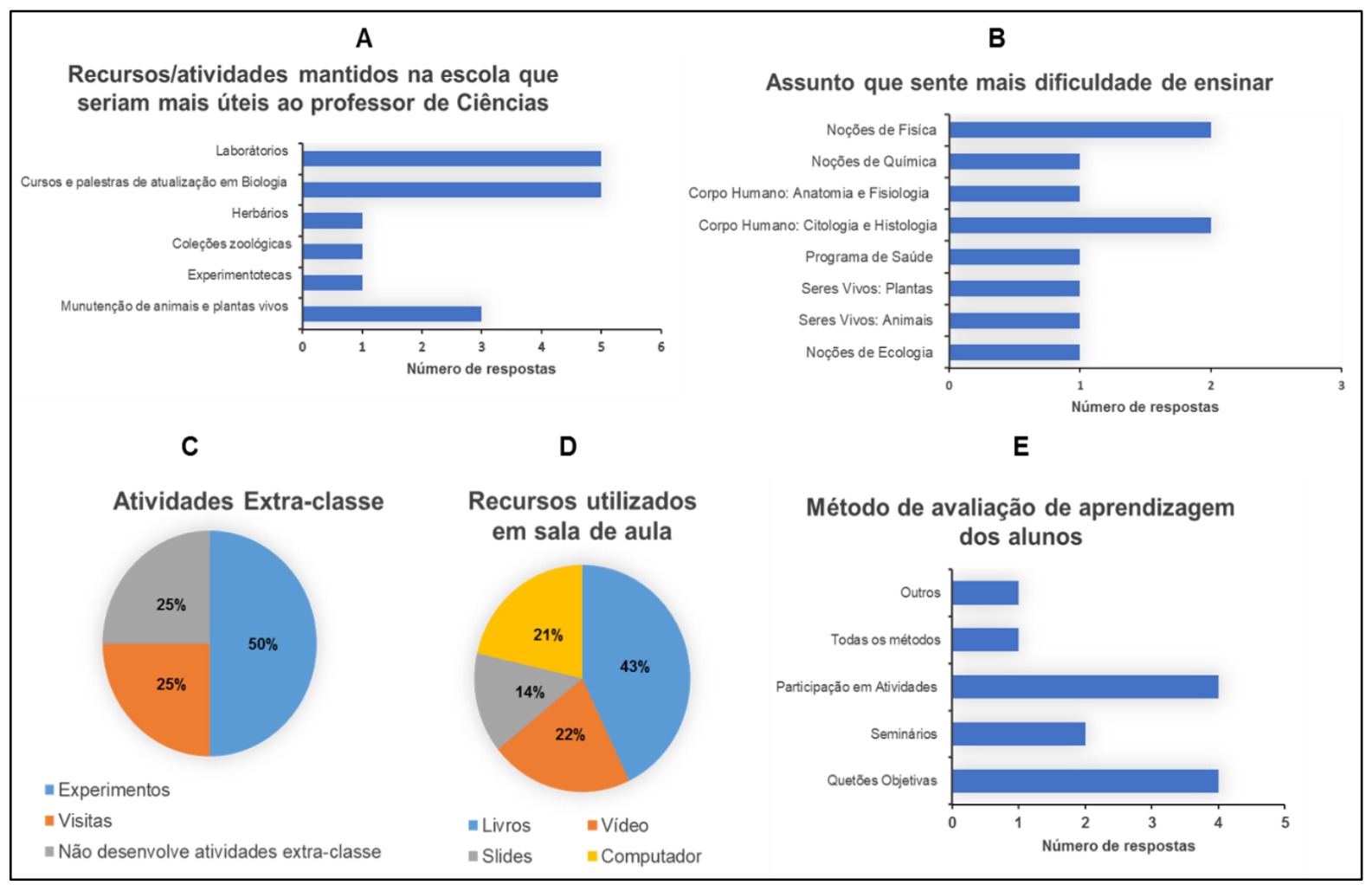

Figura 3: Formas de avaliação de Ciências das escolas públicas rurais do município de Uruçuí. Recursos/atividades mantidos na escola que seriam mais úteis ao professor de Ciências (A), Assunto que sente mais dificuldade de ensinar (B), Atividades Extraclasse (C), Recursos utilizados em sala de aula (D) e Métodos de avaliação de aprendizagem dos alunos (E).

Na concepção de Hadji (2001), os processos avaliativos devem buscar integrar, trocar e negociar os interesses comuns entre os elementos participantes (avaliador e avaliado). Isso é importante para retratar a realidade com uma compreensão que a ciência busca enfocar e contextualizar, dando mais significado à aprendizagem do aluno, valorizando o ofício da docência.

\section{Conclusões}

Ao final da pesquisa pode-se constatar que ainda existe uma grande proporção de professores que se adequam ao ensino tradicional, devido não só ao "Tradicionalismo de ensino", mas também a falta de conhecimento de outras práticas pedagógicas voltadas para ensino de Ciências/Biologia, como também a precariedade de determinados assuntos na graduação dos mesmos. São necessárias políticas de inclusão de um incentivo a programas de formação continuada, maior facilidade de acesso a revistas e jornais científicos e internet em uma abrangência local ou regional. Além disso, deve-se estimular o comprometimento dos 
educadores em se manter atualizados frente às constantes inovações científicas e tecnológicas existentes (inclusive incentivos financeiros).

\section{Referências}

ANTONIO, C. A.; LUCINI, M. Ensinar e aprender na educação do campo: processos históricos e pedagógicos em relação. Cad. CEDES, Campinas, v. 27, n. 72, p. 177-195, Mai/Ago. 2007.

ANTUNES-ROCHA M. I. Desafios e perspectivas na Formação de educadores: Reflexões a partir do curso de Licenciatura em educação do campo. Desenvolvido na FAE/UFMG. In: SOARES, Leôncio (org.) [et alii.]. Convergências e tensões no campo da formação e do trabalho docente/ - Belo Horizonte: Autêntica. p. 389-406. 2010

ARROYO, M. G. Políticas de formação de educadores do campo. Cad. CEDES, Campinas, vol. 27, n. 72, p. 157-176, maio/ago. 2007.

BARRADAS, C. J. Educação no campo: Formação Continuada de Professores do Programa Escola Ativa em Buriti (MA). 2013. 199 f. Dissertação (Mestrado em Desenvolvimento Humano: Formação, Políticas e Práticas Sociais) - Universidade de Taubaté. 2013.

BRASIL. Lei n. 9.394, de 20 de dezembro de 1996. Estabelece as diretrizes e bases da educação nacional. Diário Oficial [da] República Federativa do Brasil, Poder Legislativo, Brasília, DF, 23 dez. 1996.

BAZZO, V. L. Para onde vão as licenciaturas?: a formação de professores e as políticas públicas. Educação, Santa Maria, RS, v. 25, n. 1, p. 53-65, 2000.

CALAZANS, M. J. C. Para compreender a educação do estado no meio rural: traços de uma trajetória. In: THERRIEN, Jacques; DAMASCENO, Maria Nobre. Educação e escola no campo. Campinas: Papirus, p. 15-51. 1993.

CARVALHO, P. H. S. A formação continuada de professores da educação básica pública e a função da universidade: limites e possibilidades da ação da UFPR setor litoral. 2010. $162 \mathrm{f}$. Dissertação (Mestrado em Educação) - Universidade Federal do Paraná. 2010.

CENAFOR/MEC/INEP. A formação de professores. Bimestre, Ano I, n. 1, p. 25-27. 1986.

CEPRO. Fundação Centro de Pesquisas Econômicas e Sociais do Piauí. Diagnóstico Sócioeconômico. Município Uruçuí. 2010. Disponível em <www.cepro.pi.gov.br/download/201106/CEPRO21_0b5fab9677.pdf> Acesso em 10 Ago. 2019.

DEMO, P. Professor do futuro e reconstrução do conhecimento. Petrópolis, RJ: Vozes, 2011. 
DIEESE. Departamento Intersindical de Estatística e Estudos Socioeconômicos. Estatísticas do meio rural 2010-2011, 4. ed. Brasília, MDA, 2011.

FREITAS, D.; VILLANI, A. Formação de professores de ciências: um desafio sem limites. Investigações em ensino de ciências, v. 7, n. 3, p. 215-230, 2002.

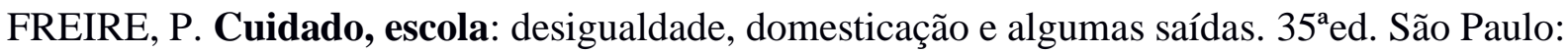
Brasiliense, 1996.

FONTELES, M. M. F.; FRANCELINO, E. V.; SANTOS, L. K. X.; SILVA, K. M.; SIQUEIRA, R.; VIANA, G. S. B.; VASCONCELOS, S. M. M.; SOUSA, F. C. F.; MONTEIRO, M. P. Reações adversas causadas por fármacos que atuam no sistema nervoso: análise de registros de um centro de fármaco vigilância no Brasil. Revista de Psiquiatria Clínica. São Paulo, v.36, n. 4, p.137-144, 2009.

FURTADO, E. D.; BRANDÃO, M. L. O que se sabe e o que se faz sobre a educação no contexto dos assentamentos rurais: colocando gás na lamparina. Educação e Debate. Fortaleza-CE, 1999.

GRAY, D. E. Pesquisa no mundo real. 2. Ed. Porto Alegre: Penso, 2012.

GEGLIO, P. C. Políticas públicas de formação continuada para professores: um estudo de cursos realizados a partir de propostas licitatórias. Ensaio: aval. pol. públ. Educ., v. 86, p, 231-257, 2015.

HADJI, C. Avaliação desmistificada. Porto Alegre: ARTMED, 2001.

HODSON, D. Towards scientific literacy: a teachers' guide to the history, philosophy and sociology of science. Roterdão: Sense Publisher, 2008.

HOOLBROK, J.; RANNIKMAE, M. The meaning of scientific literacy. Internacional Journal of Environmental \& Science Education, Den Haag, v. 4, n. 3, p. 275-288, 2009.

INEP. Instituto Nacional de Estudos e Pesquisas Educacionais Anísio Teixeira. Ministério da Educação. Panorama da Educação do Campo. Brasília, DF: INEP, p. 25, 2007.

KRASILCHIK, M. Prática de ensino de biologia. 4. ed. São Paulo: Ed. da USP, p.198, 2004.

KRUGER, V. Formação continuada de professores de ciências: o trabalho docente como referência. Educação, Porto Alegre, ano 26, n. 51, p. 69-85, 2003.

LIMA, K. E. C.; VASCONCELOS, S. D. Análise da metodologia de ensino de ciências nas escolas da rede municipal de Recife. Pesquisa em Síntese, Rio de Janeiro, v. 14, n. 52, p. 397412, jul./set., 2006.

MAIA, E. M. Educação rural no Brasil: o que mudou em 60 anos. In: Em Aberto, Brasília, v. 1, n. 9, p. 27-33, set., 1982. 
MARTINS. J. S. Capitalismo e tradicionalismo: estudo sobre as contradições da sociedade agrária no Brasil. São Paulo: Pioneira, 1975.

MARQUES, T. G. Pedagogia da Terra: significados da formação para educadores e educadoras do campo. Dissertação (Mestrado em Conhecimento e Inclusão Social em Educação). Universidade Federal de Minas Gerais. 2010.

NICOLA, J. A.; PANIZ, C. M. A importância da utilização de diferentes recursos didáticos no ensino de biologia. InFor, São Paulo, v. 2, n. 1, p.355-381, 2016.

ONOFRE, E. M. C. Escola da prisão: espaço de construção da identidade do homem aprisionado? In: ONOFRE, E. M. C. (Org.). Educação escolar entre as grades. São Carlos: EdUFSCar. p.11-28. 2007.

PARANÁ. Secretaria de estado da Educação do Paraná. Superintendência da educação. Diretrizes Curriculares de Ciências para o Ensino Fundamental. Paraná, 2008.

PARENTE, C. D. M. D. Perfil, concepções e práticas pedagógicas de professores que atuam em turmas multisseriadas de escolas públicas de Sergipe. Rev. Bras. Estud. Pedagog., Brasília, v. 95, n. 241, p. 676-695, Set/Dez. 2014.

PRINCE, M. Does Active Learning work? A review of the research. Journal of Engineering Education. Malden, v. 93, n. 3, p. 223-231, 2004.

SANTANA, M. D. S. Educar para a tolerância ou para o respeito aos povos indígenas? Práxis Educacional v. 8, nº. 13, p. 177-192 jul./dez. 2012.

SILVA, R.; PIOCHON, E. F.; COSTA, S. S. Formação Inicial e Continuada: Perfil dos professores de Ciências e Biologia de Jataí, GO. Anais da VII SEMANA DE LICENCIATURA do IFGO, Campus Jataí, n.01, 2010.

TURFI, S. Principais problemas da escola rural. Faculdade de Educação, Universidade Federal de Minas Gerais. Belo Horizonte: UFMG, FaE, DAE, Relatório de Pesquisa. 1988.

VENDRAMINI, C. R. A educação e a produção da vida no campo e na cidade: espaços de esperança? Florianópolis: Universidade Federal de Santa Catarina. 59 p. Relatório. 2014. 